\title{
PHYSICAL ACTIVITY OF STAFF AND LECTURERS OF SOFIA UNIVERSITY "ST. KLIMENT OHRIDKSI““
}

\author{
P. Hristova* \\ Sport Department, University “St. Kliment Ohridski”, Sofia, Bulgaria
}

\begin{abstract}
Bulgaria continues to be with one of the highest mortality indicators in EU and with the lowest natural nation growth. The range of risk factors to human health are determined by the economic development of the country and by the life conditions which form risk behavioral habits such as smoking, inappropriate nutrition, alcoholism and most of all low physical activity. The low level of the physical activity has a significant contribution for the deterioration of our nation's health status. A number of studies show that the immobilized lifestyle is widespread among all age groups in Bulgaria. This report presents data from a study on the lifestyle and the level of the physical activity of staff and lecturers of Sofia University "St. Kliment Ohridksi". The results show that the majority of them lead a sedentary lifestyle. The author recommends measures, which the Authorities of the University can take to improve the health status of the employees.
\end{abstract}

Key words: health status, risk factors, physical activity, lifestyle, lecturers, staff, university

\section{INTRODUCTION}

Physical activity, health and quality of life are closely related. Human body is designed to move and therefore needs regular physical activity in order to function optimally and to prevent diseases. In addition, the active life leads to many well known social and psychological benefits.

The development of our civilization alter the people's way of life. The immobilization due to the massive influx of modern technologies in everyday life, led to the alarming findings in a number of studies on the poor state of people's health. It has been long proven that sedentary lifestyle is a risk factor for the development of many chronic diseases and is one of the main causes of early death in the modern world.

World Health Organization (WHO) defines physical activity as any bodily movement

\footnotetext{
*Correspondence to: Chief ass. Petya Stoyanova Hristova, PhD, Sport Department, University "St. Kliment Ohridski”, Sofia, Bulgaria, 3-5 Aleko Konstantinov str., Sofia 1505, Bulgaria, E-mail: petya1973@yahoo.com, Mobile: +359878429842
}

produced by skeletal muscles that requires energy expenditure - including activities undertaken while working, playing, carrying out household chores, travelling, and engaging in recreational pursuits (1). The term "physical activity" should not be confused with "exercise", which is a subcategory of physical activity that is planned, structured, repetitive, and aims to improve or maintain one or more components of physical fitness. Beyond exercise, any other physical activity that is done during leisure time, for transport to get to and from places, or as part of a person's work, has a health benefit. Further, both moderateand vigorous-intensity physical activity improve health.

For adults aged 18-64 years, WHO recommends that they should do at least 150 minutes of moderate-intensity physical activity throughout the week, or do at least 75 minutes of vigorous-intensity physical activity throughout the week, or an equivalent combination of moderate- and vigorousintensity activity. For additional health benefits, adults should increase their moderateintensity physical activity to 300 minutes per week, or equivalent. Muscle-strengthening activities should be done involving major 
muscle groups on 2 or more days a week. WHO highlights that regular and adequate level of physical activity:

- improve muscular and cardiorespiratory fitness;

- improve bone and functional health;

- reduce the risk of hypertension, coronary heart disease, stroke, diabetes, various types of cancer (including breast cancer and colon cancer), and depression;

- reduce the risk of falls as well as hip or vertebral fractures;

- $\quad$ and are fundamental to energy balance and weight control.

According to World Health Organization WHO (1):

- Insufficient physical activity is one of the leading risk factors for death worldwide.

- Insufficient physical activity is a key risk factor for noncommunicable diseases (NCDs) such as cardiovascular diseases, cancer and diabetes.

- Physical activity has significant health benefits and contributes to prevent NCDs.

- Globally, 1 in 4 adults is not active enough.

- More than $80 \%$ of the world's adolescent population is insufficiently physically active.

In accordance with these warring tendencies, WHO advises that in order to increase physical activity, countries and communities must take actions to provide individuals with more opportunities to be active, such as:

- promoting physical activity through activities of daily living;

- making walking, cycling and other forms of active transportation accessible and safe for all;

- making labour and workplace policies that encourage physical activity;

The "Global Strategy on Diet, Physical Activity and Health", adopted by the World Health Assembly in 2004, describes the actions needed to increase physical activity worldwide. The "Global Recommendations on Physical Activity for Health", published by WHO in 2010, focus on primary prevention of NCDs through physical activity. It proposes different policy options to reach the recommended levels of physical activity globally, such as:

- the development and implementation of national guidelines for health-enhancing physical activity;

- the integration of physical activity within other related policy sectors, in order to secure that policies and action plans are coherent and complementary;

- the use of mass media to raise awareness of the benefits of being physically active;

- the surveillance and monitoring of actions to promote physical activity.

In response, all existing continental, overgovernment, inter-governmental organizations and national Governments have adopted and signed charters and plans for action. The relevant Ministries (including the Bulgarian) have drawn up laws and regulations for their implementation. For instance Art.48 of the Law on Physical Education and Sport of the Ministry of youth and sport in Bulgaria states:

(1) Employers and hiring authorities establish and provide conditions for sports activities and active recreation of their employees.

(2) In collective agreements, employers provide for and financially support the practice of sport and active recreation of employees.

For the past years in Bulgaria, there are already some good examples of employers who comply with the low and have made sport facilities in their buildings or provide the staff with membership cards for sport clubs. However, they are mostly from the private sector.

Regardless all the plans and policies, Bulgaria continues to be with one of the highest mortality indicators in European Union and with the lowest natural nation growth. The range of risk factors to human health are determined by the economic development of the country and by the life conditions which form risk behavioral habits such as smoking, inappropriate nutrition, alcoholism and most of all low physical activity. Low physical activity is a risk factor, which has a significant contribution to the deterioration of the health status of our population. A number of studies show that sedentary lifestyle is widespread among all age groups in Bulgaria.

A study of the risk factors for noncommunicable diseases (NCDs) held among our population (aged 25-64 years) by CINDI-BULGARIA PROGRAMME (2010), establishes that only $19.2 \%$ of men and $15.3 \%$ of women, have moderate physical exertion during the week, lasting over 30 minutes (3).

Eurobarometer's research (4) shows that $82 \%$ of the population in Bulgaria do not practice sports activities or does it once a month, as this 
share is the highest for the countries in the European Union. Only 3\% regularly practice sports activities (5 or more times a week).

Detailed data on the frequency and intensity of the physical activity of the active population in Bulgaria (25-64 years) as well as of the level of their knowledge, skills and attitudes for an active healthy life, presents a national study held in 2007 (5). The results show that over than $80.0 \%$ of the men and women asked are with insufficient physical activity during their leisure time.

According to the Ministry of youth and sport's project "It's never too late for a new beginning" (6), alarming is and the fact that there is a great deficit of educational information about the role of physical activity for the human health. "Doctors and other medical personnel exhibit a certain passivity in this direction and do not have sufficient knowledge on the problem. Only $7.0 \%$ of surveyed have received advice from a doctor or other medical staff, on the possible ways to increase physical activity. Low rates show and the other sources of information. The majority of surveyed with insufficient physical activity indicate the difficult living conditions and stress as the major cause of morbidity. Low physical activity as a factor of risk to health is referred to as low as $1.6 \%$ of the respondents. Almost every second does not know or has not responded properly about the minimum required frequency of physical exercise $(45.3 \%$ of men and $47.1 \%$ of women), and nearly $90 \%$ of them - for its duration.

In her survey (7), Tumanova found that one of the most significant changes in the last fifty years in Europe is the rapid ageing of the nations and the dramatic increase in the number of people with proven low physical and mental functioning, due to low physical activity. In addition, Peltekova (7) in her study concludes that the lack of physical activity and obesity in school and university age are prerequisites for the emergence of health problems in later period of a person's life.
Universities as high educational institutions should adhere with "Global Strategy on Diet, Physical Activity and Health" and give good example of proper care of both students and employees by promoting health-enhancing physical activity for better quality of life. Unfortunately, in reality Bulgarian Universities interpret and apply the Low on Physical Education and sport loosely and selectively and generally do not have and conduct policy for encouraging students and employees to exercise and lead an active life style.

Working as educators in the Sport Department at Sofia University "St. Kliment Ohridski" understandably, we are very concerned with the above-mentioned facts and thus:

The AIM of the presented study was:

1. To establish how active is the way of life of Sofia University "St. Kliment Ohridski" employees.

2. To recommend measures, which the Authorities of the University can take to improve the health status of the employees.

\section{METHODS AND INSTRUMENTS:}

For the purposes of the study, we used the Descriptive - explicative method. We designed questioner of ten closed questions, where interviewed could point out only one of 3 or 4 answers. The study was conducted in September 2018.

PARTICIPANTS were 100 people - 50 administration staff and 50 lecturers at Sofia University "St. Kliment Ohridski", aged 24 to 65 years, of which 57 women and 43 men.

\section{STATISTICAL METHODS}

For analyzing the received data, we used the Percent's analyses.

\section{RESULTS AND DISCUSSION}

As recommended by WHO, getting to and from places/work by walk or bicycle is a great way to give yourself enough exercise. As shown in Figures 1 and 2, even though the majority of the interviewed live close by their work (74\% of the staff and $60 \%$ of lecturers), they get to and from there by car or public transport (88\% of staff and $78 \%$ of lecturers) 


\section{Distance to work}

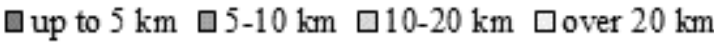

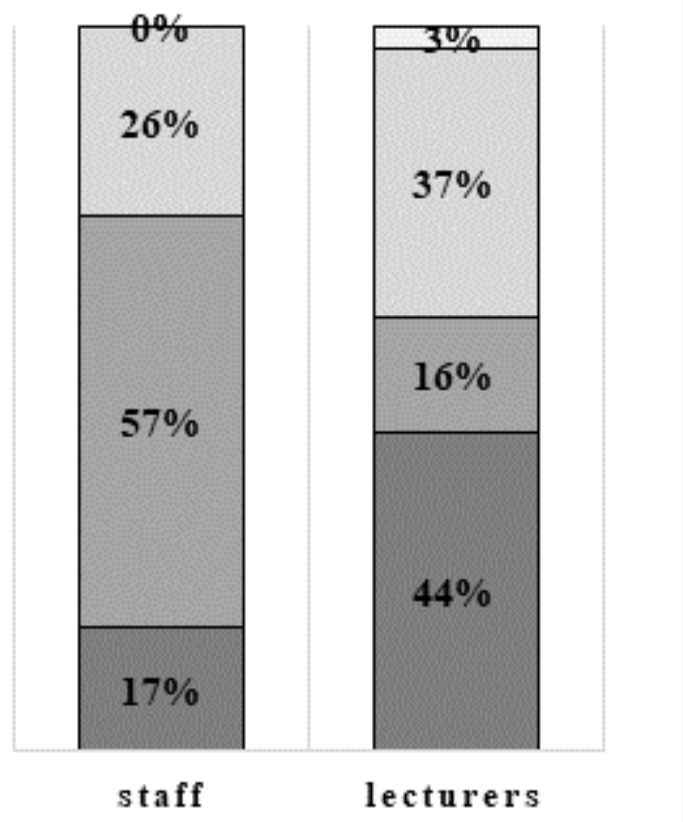

Figure 1. Distance to work

Once at work (Figure 3), the university's employees spend a lot of time sitting - $87 \%$ of administration staff and $60 \%$ of lecturers do so from three to eight hours per day. Moreover, in their leisure time, they also sit for 2 to over 4

\section{Time sitting during work}

$\square$ up to 1 hour $\square 1-3$ hours $\square 3-5$ hours $\square 6-8$ hours

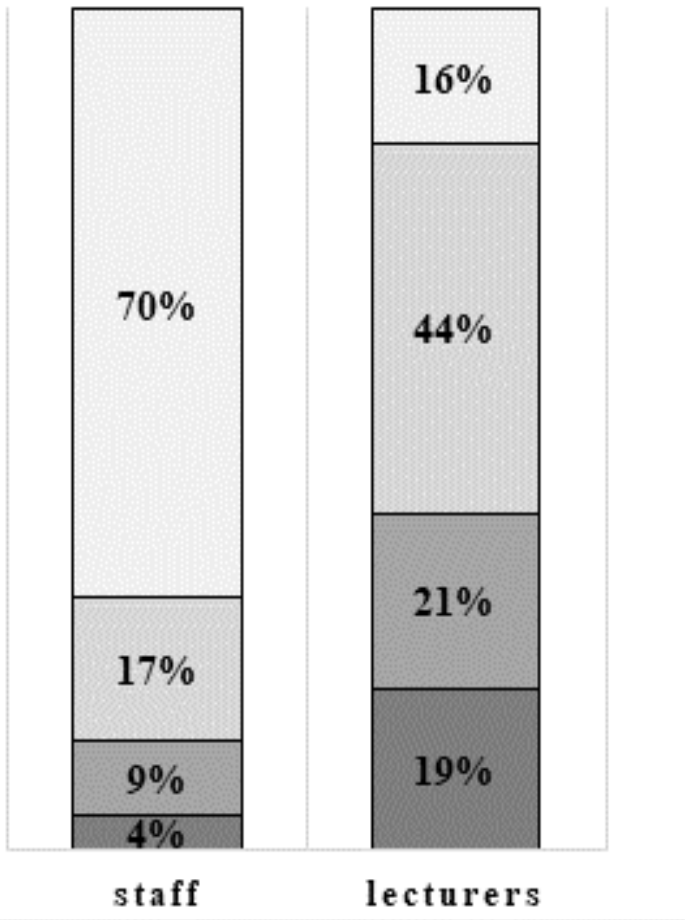

Figure 3. Time sitting during work

\section{Means of transportation}

$\begin{array}{ll}\square \text { by walk } & \square \text { by car } \\ \square \text { public transport } & \square \text { bicycle }\end{array}$

$\square$ combination

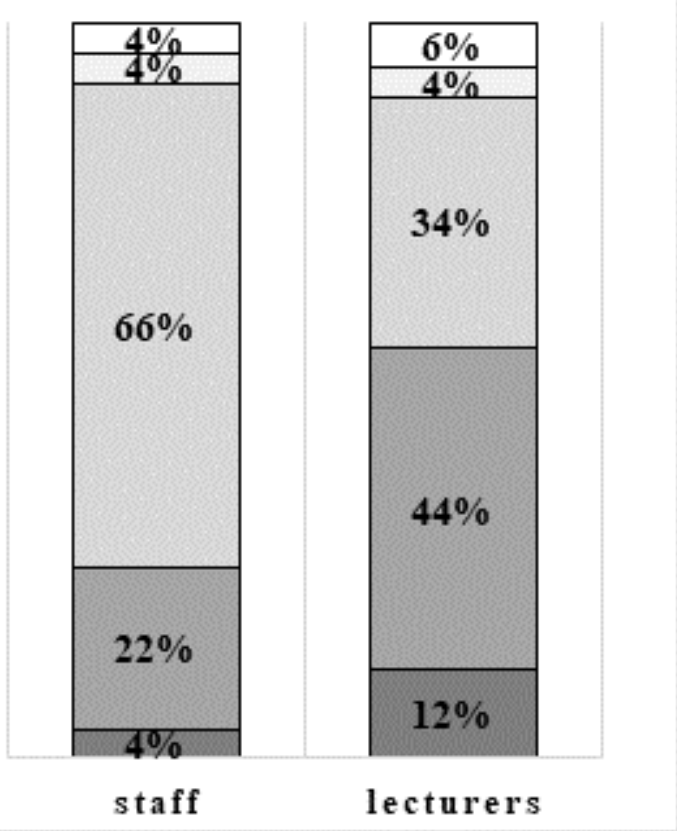

Figure 2. Means of transportation to work

hours while surfing the Internet, watching TV, finishing work at home (Figures 4 and 5) $74 \%$ of the administrators and $78 \%$ of lecturers.

\section{Sitting during spare time}

Dup to 2 hours $\quad 2-4$ hours $\square$ over 4 hours

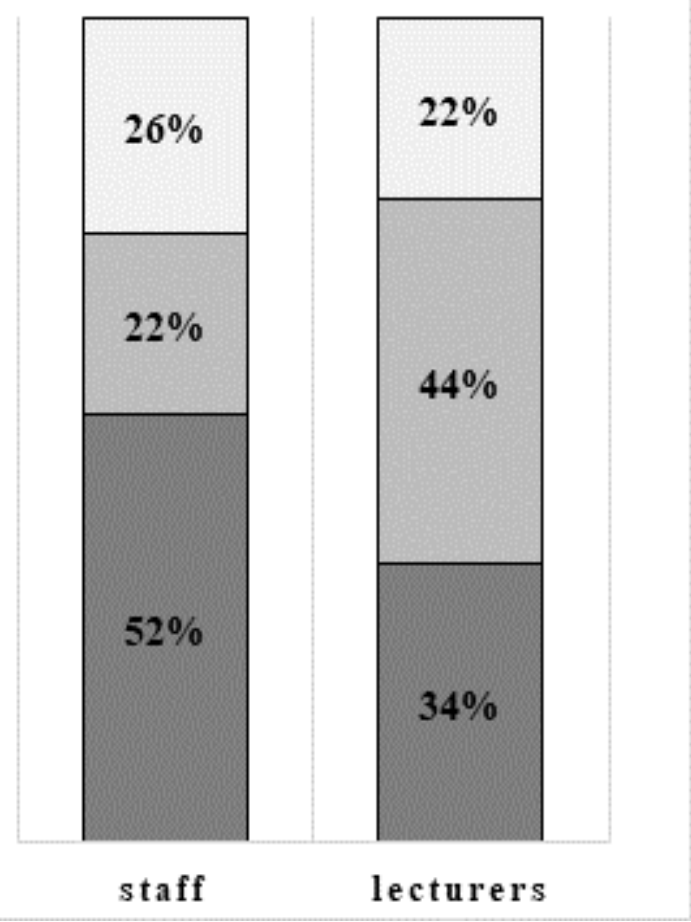

Figure 4. Sitting during spare time 


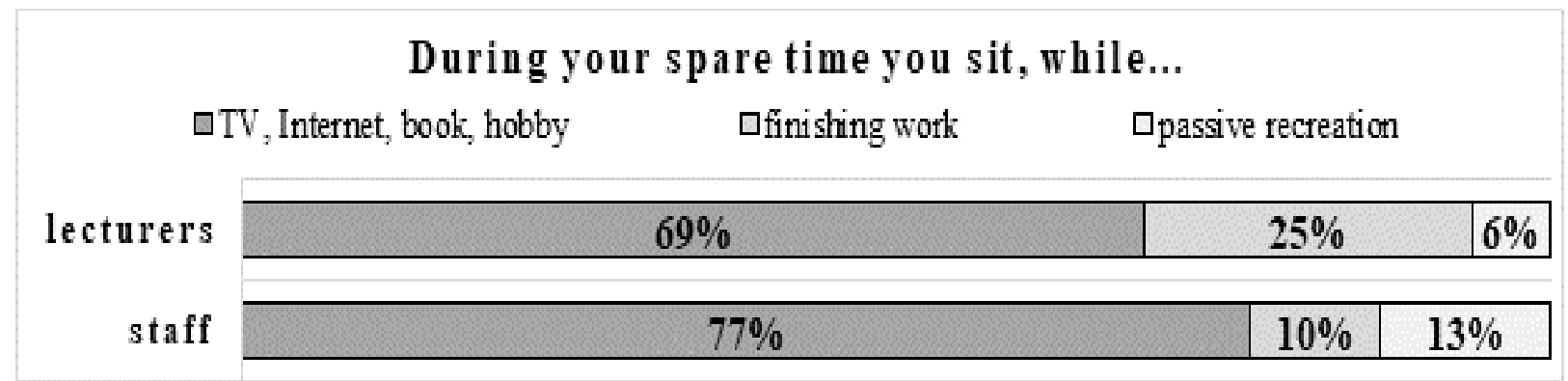

Figure 5. During your spare time you sit, while...

The majority of the employees (Figure 6) do not exercise at all or do it one or two times a month (61\% of the staff and $72 \%$ of lecturers). The number of people who do workouts with moderate to vigorous intensity three to five times a week (as recommended by WHO) are $22 \%$ of the administrators and only $9 \%$ of the lecturers.

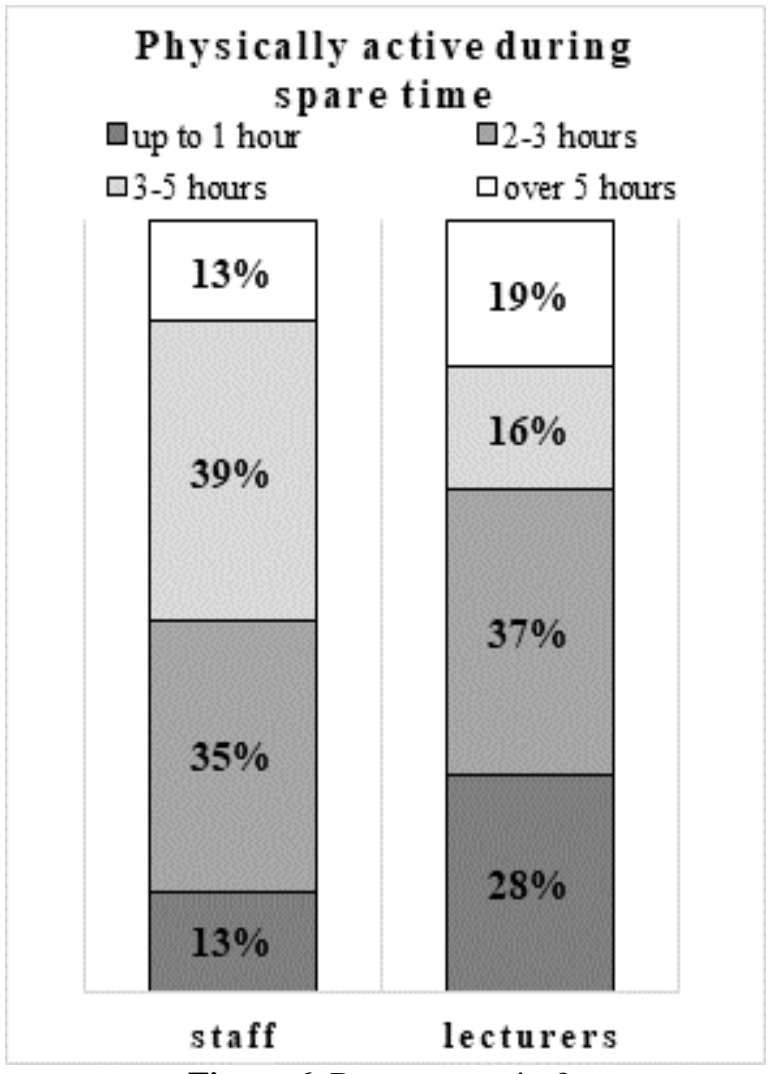

Figure 6. Do you exercise?

The usual excuse "lack of time", is what limits the most the lecturers to exercise $(66 \%)$. For the administrators it is also the inconvenience they fill, when comparing their own physical abilities with those of others, as well as "other
As seen in Figure 7, both administration staff and lecturers are only physically active when doing household work or walking the pet, which, as stated above, do not contribute enough to reach the required level of health enhancing physical activity.

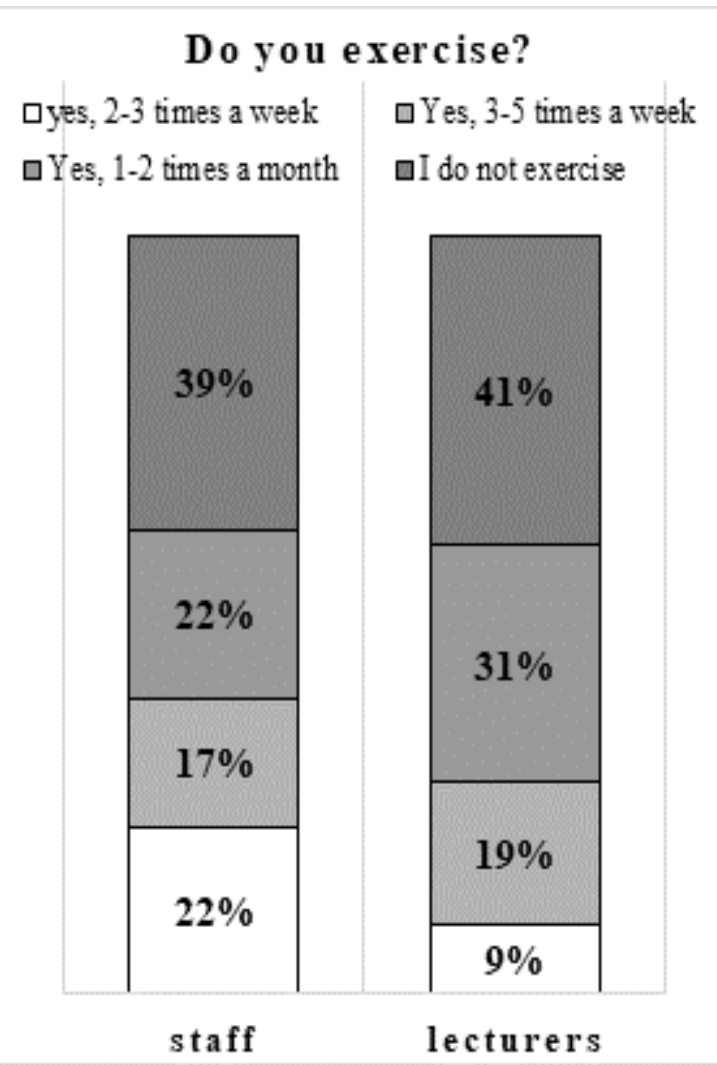

Figure. 7. Physically active during spare time

reasons" without being specified (Figure 8). At the same employees declare that they are not $(65 \%$ of the staff and $50 \%$ of the lecturers) or relatively $(26 \%$ of staff and $34 \%$ of lecturers) satisfied with the level of their physical activity (Figure 9). 
HRISTOVA $P$.

\section{What limits you \\ to exercise/play sport?}

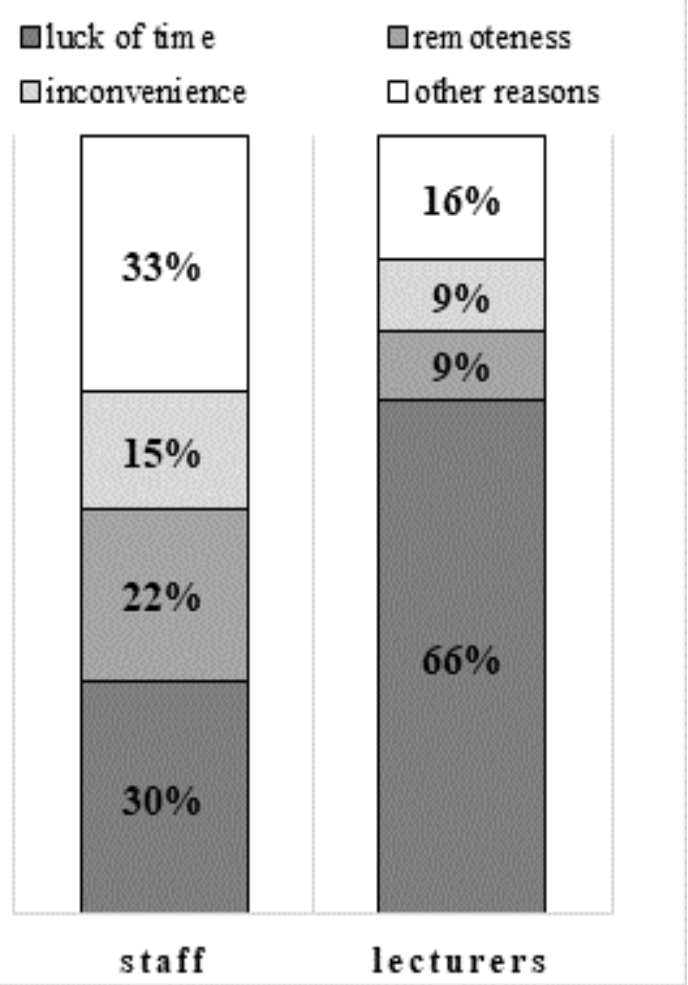

Figure 8. Reasons not to exercise/play sports

If there were established/provided conditions for sports activities at work, $52 \%$ of the administrators and $41 \%$ of the lecturers would take that opportunity and exercise in their lunch break (Figure 10). And most probably those who are not sure will do so too.

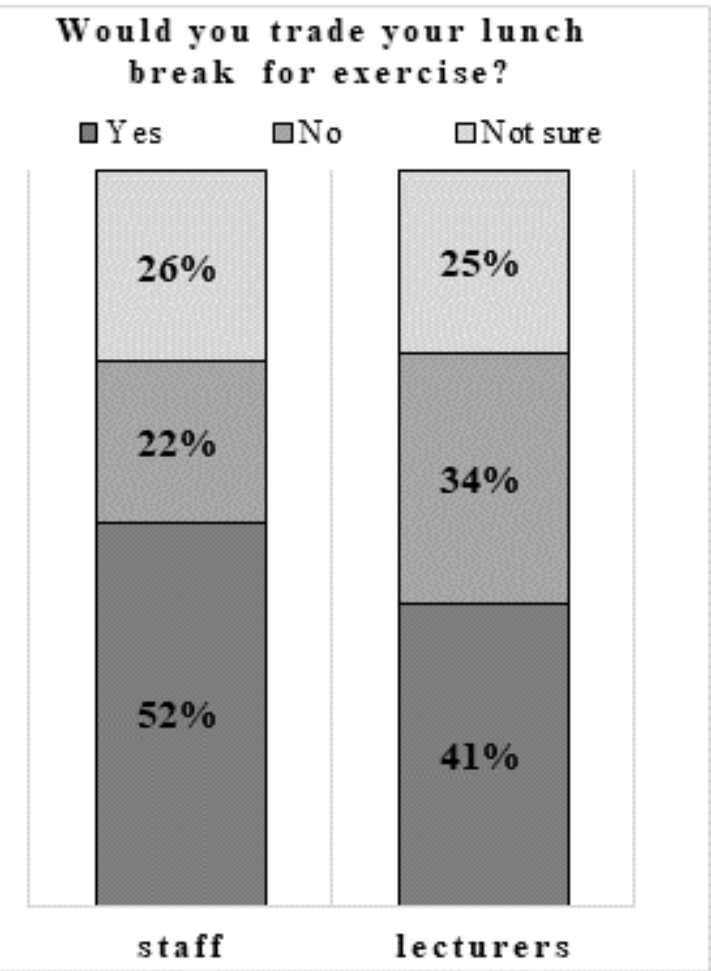

Figure 10. Would you trade your lunch-break for exercise?

\section{Are you satisfied with the level of your physical activity?}

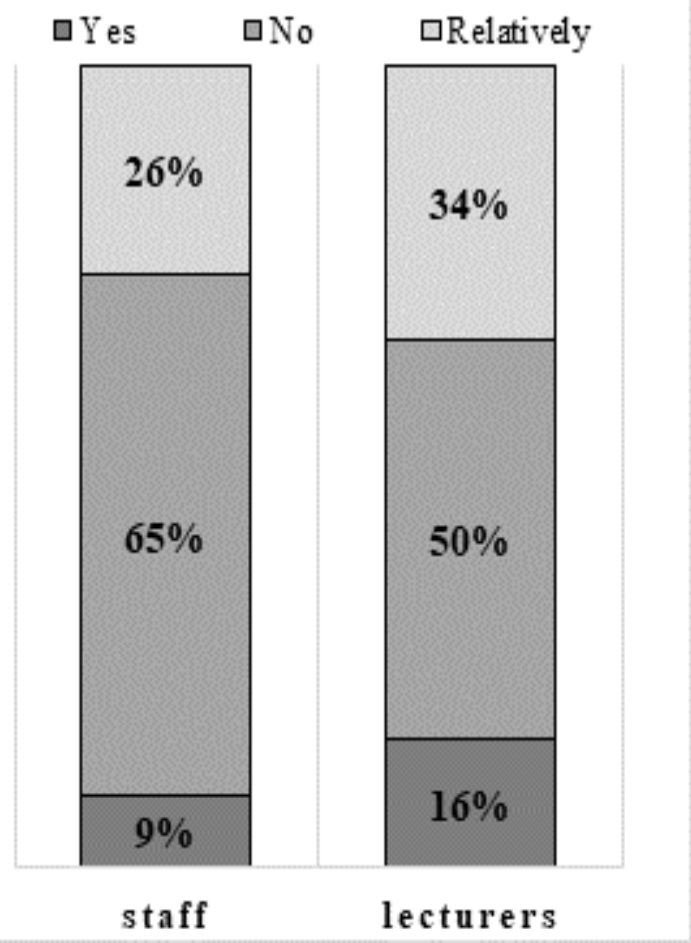

Figure 9. Are you satisfied with the level of your

\section{CONCLUSIONS}

To our regret, the results from our study show that the majority of Sofia University "St. Kliment Ohridski" employees lead a sedentary lifestyle. Generally, they do not exercise and have good excuses for not doing so. We believe that they lack knowledge about how important for their health is to exercise on a regular basis. As an employer, the University does not provide conditions for sports activities and active recreation of its employees and there is no clear policy for raising awareness of the benefits of being physically active.

\section{RECOMMENDATIONS}

- The University's authorities should adopt and lead an active educational policy aimed at raising awareness of the importance and benefits of being physically active among its employees.

- The University's authorities should take into account the recommended actions, provided in Art.48 of the Law on Physical Education and Sport:

(3) Employers and hiring authorities establish and provide conditions for sports activities and active recreation of their employees.

(4) In collective agreements, employers provide for and financially support the practice of sport and active recreation of employees. 
HRISTOVA $P$.

\section{REFERENCES}

1. www.who.int/ncds/prevention/physicalactivity

2. Law on Physical Education and Sport, promulgated in SN № 86 on 18.10.2018 year.

3. A study of the risk factors for noncommunicable diseases (NCDs) held among our population (aged 25-64 years) by CINDI-BULGARIA PROGRAMME, 2007, BSOZ, book.3, 2010.

4. Special Eurobarometer, Sport \& Physical Activity, March 2010

5. National study of the risk factors for the health of the population aged 25-64 years (2010), Ministry of health.
6. „Medical facts related to physical activity“ (2011), Project „It's never too late for a new beginning", Ministry of youth and sport.

7. Tumanova, B. Improving the quality of life of older people through exercises in the aquatic environment, Book "Modern tendencies in Physical education and sport", ISSN 1314-2275, Sofia, 2018.

8. Peltekova, I. Monitoring of the physical activity in the everyday life of the young generation. „Pedagogical environment at the University as a space for professional and personal development of future specialists”, ISBN 978-954-490-161-5, EKS-PRESS Publishing, c. 555-557, Gabrovo, 2010. 